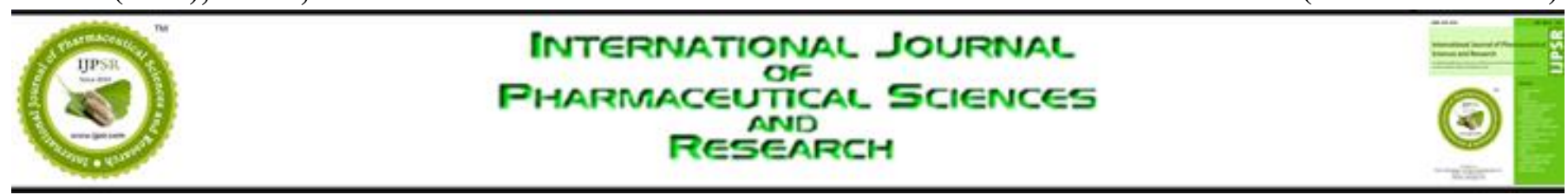

Received on 05 November, 2015; received in revised form, 22 December, 2015; accepted, 05 February, 2016; published 01 April, 2016

\title{
QUALITY BY DESIGN APPROACH FOR THE DEVELOPMENT AND VALIDATION OF SAXAGLIPTIN BY RP-HPLC WITH APPLICATION TO FORMULATED FORMS
}

\author{
Shubhangi C. Daswadkar ${ }^{* 1}$, Madhumita A. Roy ${ }^{1}$, Sanjay G. Walode ${ }^{2}$ and Mahendra Kumar CB ${ }^{3}$
}

Department of Pharmaceutical Chemistry ${ }^{1}$, Padm. Dr. D. Y. Patil College of Pharmacy, Akurdi, Pune411044, Maharashtra, India

Department of Pharmaceutical Chemistry ${ }^{2}$, Sinhgad Institute of Pharmaceutical Sciences, Kusgaon (Bk), Lonavala, Pune- 410 401, Maharashtra, India

Department of Pharmaceutical Chemistry ${ }^{3}$, St. Mary’s College of Pharmacy, H.No.9-1-248, St. Francis Street, Secunderabad-500025, Andhra Pradesh, India

Key words:

QbD, Saxagliptin,

antidiabetic, Stability-indicating method, ICH guidelines

\section{Correspondence to Author:}

Shubhangi C. Daswadkar

Assistant Professor,

Department of Pharmaceutical

Chemistry, Dr. D. Y. Patil

Educational Complex, Padmashree

Dr. D. Y. Patil College of Pharmacy,

Akurdi, Pune-411044, Maharashtra, India.

E-mail: shubhangi1485@rediffmail.com

\begin{abstract}
Quality by Design (QbD) is a philosophy that refines the level of knowledge associated with a product that uses process understanding to deliver a product with the desired critical quality attributes. The objective of this present study was to develop and demonstrate an integrated multivariate approach to develop and quantify the constituent concentrations of saxagliptin drug in its pure and formulated forms. The method was developed using a mobile phase acetonitrile: water $(\mathrm{pH} 3),(20: 80 \mathrm{v} / \mathrm{v})$ on an Agilent, TC C18 $(250 \times 4.6 \mathrm{~mm})$ $5 \mu \mathrm{m}$ column and flow rate $1.0 \mathrm{ml} / \mathrm{min}$ which was optimized with help of design expert software and validated according to ICH Q2 guideline and application of this method to different stress condition of saxagliptin. The detector linearity was established in concentrations ranging from $10-90 \mu \mathrm{gmL}-1$, the regression coefficient was 0.9993 . The method fulfilled validation criteria and was shown to be sensitive, with limits of detection (LOD) and quantitation (LOQ) of 0.003 and $0.010 \mu \mathrm{gmL}-1$, respectively. The percentage relative standard deviations for robustness and ruggedness were observed within the range of 0.28 and 0.57 . The drug was subjected to acidic, alkali, neutral, oxidative, heat and photo degradation stress. Drug shows significantly degraded in acidic and alkali condition while remain stable in other conditions. The high recovery and low relative standard deviation confirm the suitability of these methods can be employed for the routine analysis of tablet containing saxagliptin.
\end{abstract}

INTRODUCTION: Quality by design is a systematic approach to development that begins with predefined objectives and emphasizes product and process understanding and process control, based on sound science and quality risk management ${ }^{1}$.

\begin{tabular}{|l|c|}
\hline QUICK RESPONSE CODE & $\begin{array}{c}\text { DOI: } \\
\text { 10.13040/IJPSR.0975-8232.7(4).1670-77 }\end{array}$ \\
\cline { 2 - 2 } & $\begin{array}{c}\text { Article can be accessed online on: } \\
\text { www.ijpsr.com }\end{array}$ \\
\hline
\end{tabular}

The objective of the $\mathrm{QbD}$ initiative is to demonstrate both understanding and control of pharmaceutical processes to deliver high quality pharmaceutical products while affording opportunities for continuous improvement. $\mathrm{QbD}$ delivers a better understanding of method capabilities and limitations and ensures a superior chance of successful downstream method validation and transfer. It has become an important paradigm in the pharmaceutical industry since its introduction by the US Food and Drug Administration ${ }^{2-4}$. The QbD concept can be extended to analytical methods ${ }^{5-8}$. The analytical 
methods used for the analysis of active pharmaceutical ingredients (API) and drug products are an integral part of the $\mathrm{QbD}$.

Saxagliptin (Fig.1) is chemically (1S, 3S, 5S) -2[(2S) -2-amino-2- (3-hydroxy -1-adamantyl)acetyl] -2-azabicyclo [3.1.0]hexane-3-carbonitrile is oral hypoglycemic (anti-diabetic drug) of the new dipeptidyl peptidase-4 (DPP-4) inhibitor class of drugs. DPP-4 inhibitors represent a new therapeutic approach to the treatment of type 2 diabetes mellitus. They inhibit the inactivation of incretins, resulting in the stimulation of glucose-dependent insulin release and the reduction of glucagon levels 9

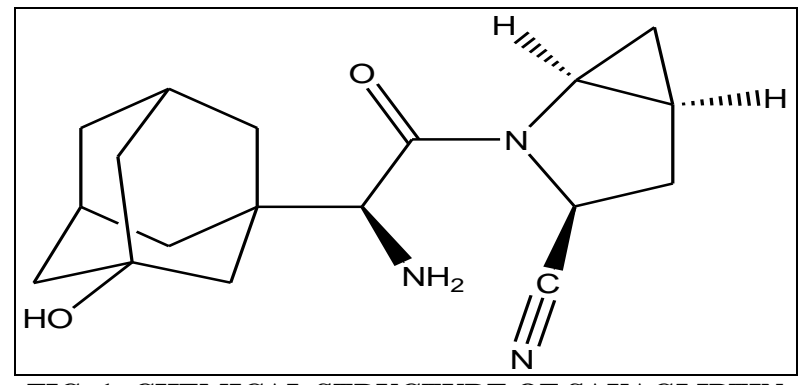

FIG. 1: CHEMICAL STRUCTURE OF SAXAGLIPTIN

Several analytical methods have been developed for quantitative analysis of Saxagliptin in bulk and pharmaceutical formulations like UV-spectrophotometric method ${ }^{10-13}$, Reverse Phase-High Performance Liquid Chromatography (RP-HPLC) method 14-18, RP-HPLC with fluorescence detection method in human plasma ${ }^{19}$, High Performance Thin Layer Chromatographic Method ${ }^{20}$. Ultra performance liquid chromatography/tandem mass spectrometry (UPLC-MS/MS) method has been developed for quantification of Saxagliptin in rat plasma ${ }^{21}$. Liquid chromatography and tandem mass spectrometry (LC-MS/MS) method has been developed and validated for simultaneous analysis of Saxagliptin and its major metabolite ${ }^{22}$.

LC-ESI-MS/MS method has been developed for estimation of saxagliptin and its forced degradation products ${ }^{23}$. Method development approach with RP-HPLC specifically focused on pharmaceutical development in a $\mathrm{QbD}$ environment for saxagliptin has not been reported anywhere. Therefore, there is an unmet need to investigate a systematic HPLC method development approach for pharmaceutical development using QbD principles to ensure the quality of the method throughout the product lifecycle. The primary objective of this study was to implement $\mathrm{QbD}$ approach to develop and validate an RP-HPLC method that could separate drug in the bulk and formulated forms from its potential related substances and to establish an in depth understanding of the method and build in the quality during the method development to ensure optimum method performance over the lifetime of the product with a suitable degradation data.

\section{MATERIALS AND METHODS:}

Chemical and reagents: A sample of saxagliptin was obtained as a gift from Neul and laboratories ltd., Hyderabad, Telangana, India. Saxagliptin containing tablets; Onglyza (5 mg) (AstraZeneca UK Limited), were procured from the local market. All HPLC-grade acetonitrile was obtained from Merck, Mumbai, India. Hydrochloric acid, sodium hydroxide and hydrogen peroxide $(30 \%)$ were obtained from Merck, India. Doubly distilled water was used throughout the investigation.

\section{Instrumentation and chromatographic conditions:}

The HPLC system, Agilent 1120 compact with manual Rheodyne injector facility operates at $20 \mu \mathrm{L}$ capacity per injection was used. The instrumentation was controlled by use of EZChrom Elite Compact software. The column used was Agilent TC C18 $(250 \times 4.6 \mathrm{~mm}) 5 \mu \mathrm{m}$ and the detector consisted of UV/VIS. Optimization of chromatographic conditions was carried out using water (pH3 with ortho phosphoric acid): acetonitrile $(80: 20 \mathrm{v} / \mathrm{v})$ as mobile phase. The analysis was carried out under gradient conditions using flow rate $1.0 \mathrm{mLmin}^{-1}$ at $18^{0} \mathrm{C}$ and chromatograms were recorded at $211 \mathrm{~nm}$.

\section{Preparation of standard stock solution:}

Weighed accurately $10 \mathrm{mg}$ of saxagliptin and transferred to $100 \mathrm{ml}$ volumetric flask, add $25 \mathrm{~mL}$ of mobile phase and sonicate for $15 \mathrm{~min}$ and volume was made up to mark with mobile phase $(100 \mu \mathrm{gmL}-1)$.

\section{Procedure for preparation of calibration curve} Working solutions containing $10-90 \mu \mathrm{gmL}-1$ saxagliptin were prepared by serial dilutions of 
aliquots of the stock solution. Aliquots of $20 \mu \mathrm{L}$ were injected (six injections) and eluted with the mobile phase under the reported chromatographic conditions. The average peak area versus the concentration of saxagliptin in $\mu \mathrm{g} / \mathrm{ml}$ was plotted. Alternatively, the corresponding regression equation was derived using mean peak area concentration data and the concentration of the unknown was computed from the regression equation.

\section{Preparation of Sample Solutions:}

Twenty tablets of ONGLYZA were weighed and finely powdered. An accurately weighed powder equivalent to $10 \mathrm{mg}$ was taken to $100 \mathrm{~mL}$ volumetric flask and dissolved in $50 \mathrm{ml}$ diluent and finally volume was made up to the mark with the diluent to obtain a concentration of $100 \mu \mathrm{gmL}-1$. This solution was sonicated for $10 \mathrm{~min}$ and filtered. Filtration is done to remove the excipients and to avoid clogging of sample applicator syringe. The amount of drug present in the sample solutions were determined using calibrated curves of standard saxagliptin in Table 3 .

\section{Method validation: ${ }^{24}$}

\section{Accuracy and Precision:}

To determine the accuracy and intra-day precision, pure saxagliptin solutions at three different concentrations were analyzed in six replicates during the same day. The same procedure was followed in different days for the inter day precision. Mobile phase was injected as blank solution before sample injection and the RSD (\%) values of peak area and retention time were calculated.

\section{Limits of Detection (LOD) and Quantification (LOQ):}

The LOD and LOQ were obtained by signal to noise $(\mathrm{S} / \mathrm{N})$ ratio method. LOQ and LOD were obtained by a series of dilutions of the saxagliptin stock solution. Precision study was performed at LOQ level also. LOQ solution was injected six times and calculated the \% RSD values for the obtained peak area and retention time.

\section{Linearity:}

Linearity of test solutions for the assay method was prepared from saxagliptin stock solution at nine concentration levels from 10 to $90 \%$ of assay analyte concentration $(10,20,30,40,50,60,70,80$ and $90 \mu \mathrm{gmL}-1)$. The peak area versus concentration data was treated by least-squares linear regression analysis. Linearity test solutions for the method were prepared by diluting stock solution to the required concentrations.

\section{Robustness and Ruggedness:}

To determine the robustness of the method the experimental conditions were deliberately changed. The flow rate of the mobile phase $(1.0 \pm$ $\left.0.2 \mathrm{mLmin}^{-1}\right)$, column oven temperature $\left(25 \pm 2^{\circ} \mathrm{C}\right)$, mobile phase composition (actual $\pm 10 \%$ ), and detection wavelength $(211 \pm 1 \mathrm{~nm})$ were the varied parameters. In each case the \%RSD values were calculated for the obtained peak area and retention time. The number of theoretical plates and tailing factors were compared with those obtained under the optimized conditions. Three different columns of same dimensions were used for the analyses. The studies were performed on the same day and on three different days by three different analysts for three different concentrations of saxagliptin (triplicate injections). The area obtained from each concentration was compared with that of the optimized one. The relative standard deviation values were evaluated for each concentration.

\section{Force Degradation Studies:}

All stress decomposition studies were performed at drug concentration of $10 \mu \mathrm{gmL}-1$ in mobile phase. Acid hydrolysis was performed in $0.1 \mathrm{M} \mathrm{HCl}$ at $80^{\circ} \mathrm{C}$ for $2 \mathrm{~h}$. The study in alkaline condition was carried out in $0.1 \mathrm{M} \mathrm{NaOH}$ at $80^{\circ} \mathrm{C}$ for $3 \mathrm{~h}$. The study in neutral condition was carried out in water at $80^{\circ} \mathrm{C}$ for $3 \mathrm{~h}$. Oxidative studies were carried out at $80^{\circ} \mathrm{C}$ and $3 \%$ hydrogen peroxide for $2 \mathrm{~h}$. For photolytic degradation studies, pure drug in solid state was exposed to 1.2 million lux hours in a photo stability chamber [33]. Additionally, the drug powder was exposed to dry heat at $105^{\circ} \mathrm{C}$ for $2 \mathrm{~h}$. Samples were withdrawn at appropriate time and subjected to HPLC analysis after suitable neutralisation and dilution.

\section{RESULTS:}

The method development consisted of two phases: the first is screening and the second is optimisation. 
Screening: Solubility of the drug is the main criteria for any method to develop and then the UV response of the product at varying wavelengths. Saxagliptin was found soluble in an acetonitrile. A $50 \mu \mathrm{gmL}^{-1}$ solution showed excellent response at $211 \mathrm{~nm}$ when it was scanned from 400 to $200 \mathrm{~nm}$ in a UV spectrophotometer. In HPLC, variables such as mobile phase, buffer, temperature, sample concentration, and $\mathrm{pH}$ were varied by keeping one parameter (stationary phase) constant. Summarized observations are made as per the Table 1.

TABLE 1: SCREENING: SUMMARY OF METHOD SELECTION

\begin{tabular}{lccc}
\hline S. no. & Column & Observations & Remarks \\
\hline 1. & ZORBAX C18 & Asymmetrical peak & Not satisfactory \\
2. & $(250 \times 4.6 \mathrm{~mm}), 5 \mu \mathrm{m}$ & & Not satisfactory \\
& ZORBAX C8 & Asymmetrical peak & Not satisfactory \\
3. & $(150 \times 4.6 \mathrm{~mm}), 5 \mu \mathrm{m}$ with tailing & Split peak & Not satisfactory \\
ZORBAX Cyano & $(150 \times 4.6 \mathrm{~mm}), 5 \mu \mathrm{m}$ & Asymmetrical peak & satisfactory \\
5. & Eclipse XDB-C 18 & & \\
\hline
\end{tabular}

\section{Optimisation:}

Agilent TC C18 (250 X $4.6 \mathrm{~mm}$ ) $5 \mu \mathrm{m}$ column, was found suitable and the fine tuning of the method was performed with suitable adjustment of $\mathrm{pH}$. All the trials are as shown in Table $\mathbf{2}$ and chromatograms are as shown in Fig.2.

TABLE 2: FINAL OPTIMIZATION OF pH WITH AGILENT TC C18 $(250 \times 4.6$ MM) 5MM COLUMN

\begin{tabular}{cccc}
\hline Sr. No. & Trails Taken & Observations & Remarks \\
\hline 1. & ACN: water $(\mathrm{pH} 3)(20: 80 \mathrm{v} / \mathrm{v})$ & Peaks found symmetrical & Satisfactory \\
2. & ACN: water $(\mathrm{pH} 3.5)(20: 80 \mathrm{v} / \mathrm{v})$ & Broad peak & Not satisfactory \\
3. & ACN: water $(\mathrm{pH} 4)(20: 80 \mathrm{v} / \mathrm{v})$ & Broad peak and late elution & Not satisfactory \\
4. & ACN: water $(\mathrm{pH} 5)(20: 80 \mathrm{v} / \mathrm{v})$ & Broad Peak and elute before1min & Not satisfactory \\
\hline
\end{tabular}

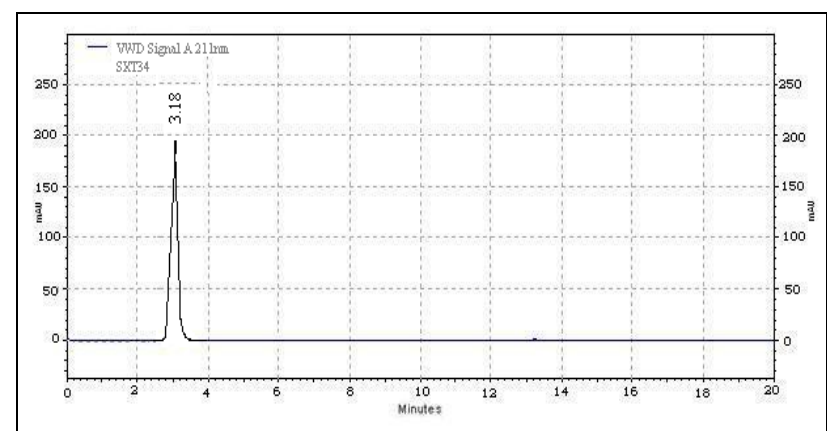

(a) ACN:Water (pH3) (20:80\% v/v)

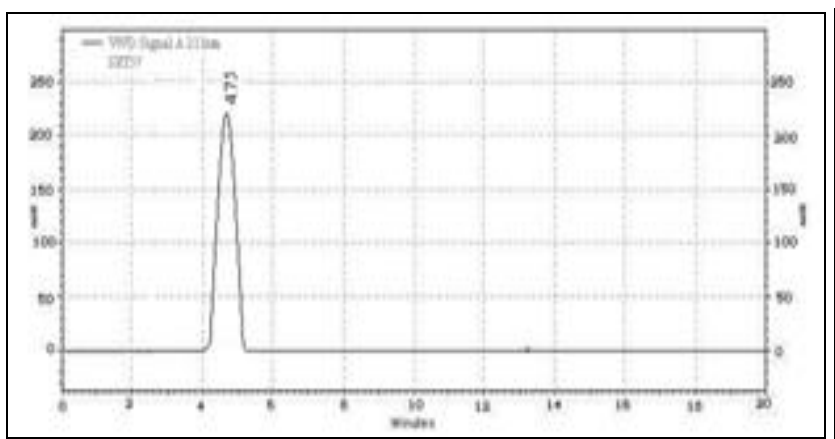

(c) ACN: Water (pH4) (20:80\% v/v)

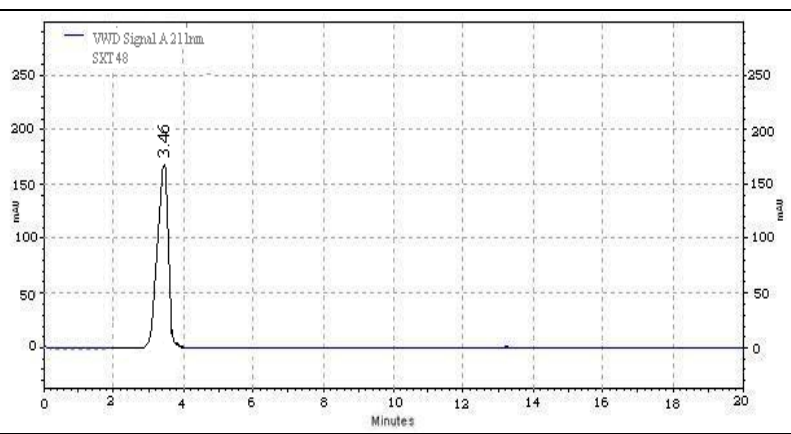

(b) ACN: Water (pH3.5) (20:80\% v/v)

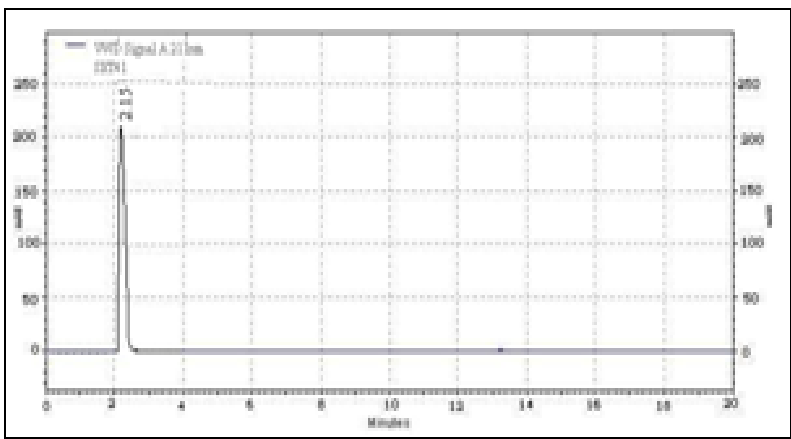

(d) ACN: Water (p5) (20:80\%v/v)

FIG.2: METHOD OPTIMIZATION AT DIFFERENT pH CONDITIONS. 
Final Method Conditions:

Column: Agilent TC C18 (250 X $4.6 \mathrm{~mm}) 5 \mu \mathrm{m}$, Oven temp.: $25^{\circ} \mathrm{C}$, Mobile phase: $\mathrm{ACN}$ : Water
(pH3 with ortho phosphoric acid) (20:80\%v/v), Runtime: $10 \mathrm{~min}$, Flow rate: $1 \mathrm{~mL} / \mathrm{min}$, Wavelength: $211 \mathrm{~nm}$.

TABLE 3: ASSAY DATA OF MARKETED FORMULATION

\begin{tabular}{cccccc}
\hline Component & Formulation & $\begin{array}{c}\text { Amount } \\
\text { present } \\
(\mathbf{m g})\end{array}$ & $\begin{array}{c}\text { Amount } \\
\text { found } \\
(\mathbf{m g})\end{array}$ & \% Estimated & \%RSD \\
\hline Saxagliptin & Onglyza & 5 & 4.98 & 99.60 & 0.57 \\
& & 5 & 5.02 & 100.40 & 1.98 \\
& & 5 & 5.01 & 100.20 & 1.83 \\
\hline
\end{tabular}

\section{Validation of the Method:}

The described method for the assay of saxagliptin was validated as per the current ICH Q2 (R1) guidelines.

TABLE 4: LINEARITY AND REGRESSION PARAMETERS WITH PRECISION DATA

\begin{tabular}{cc}
\hline Parameters & Values \\
\hline Linear range, $\mu \mathrm{gmL}$ & $10-90$ \\
Limit of quantification(LOQ), $\mu \mathrm{gmL}^{-1}$ & 0.003 \\
Limit of detection(LOD), $\mu \mathrm{gmL}^{-1}$ & 0.010 \\
Regression equation & $Y=384792 \mathrm{x}+421527$ \\
Slope(b) & 384792 \\
Intercept (a) & 421527 \\
Correlation coefficient $\left(\mathrm{r}^{2}\right)$ & 0.9993 \\
\hline
\end{tabular}

\section{Linearity:}

A calibration curve was obtained for saxagliptin stock solution. There sponse of the drug was found to be linear in the investigation concentration range from 10 to $90 \mu \mathrm{g} \mathrm{mL}-1$ and the linear regression equation was $Y=384792 x+421527$ with correlation coefficient of 0.9993 , where $\mathrm{Y}$ is the mean peak area. The LOD and LOQ values and their standard deviations were evaluated and presented in Table 4. These results confirm the linear relation between the mean peak area and concentration as well as the sensitivity of the method.

\section{Accuracy and Precision:}

The percentage relative error which is an index of accuracy is $\leq 0.259$ andisindicativeofhigh accuracy. The calculated percentage relative standard deviation (\%RSD) can be considered to be satisfactory. The results obtained for the evaluation of precision and accuracy of the method is compiled in Tables 5 and $\mathbf{6}$.

TABLE 5: RESULTS OF ACCURACY STUDY $(n=6)$.

\begin{tabular}{ccccc}
$\begin{array}{c}\text { Concentration } \\
\text { Injected } \\
\left(\boldsymbol{\mu} \mathbf{g ~ m L}^{-\mathbf{1}}\right)\end{array}$ & $\begin{array}{c}\text { Concentration found } \\
\left(\boldsymbol{\mu g} \mathbf{~ m L}^{-\mathbf{1}}\right) \pm \boldsymbol{S D}\end{array}$ & Recovery (\%) & $\begin{array}{c}\text { RSD } \\
(\boldsymbol{\%})\end{array}$ & $\begin{array}{c}\text { SEM } \\
10\end{array}$ \\
18 & $10.01 \pm 0.026$ & 100.10 & 0.259 & 0.0086 \\
20 & $18.04 \pm 0.020$ & 100.22 & 0.110 & 0.0066 \\
22 & $19.99 \pm 0.036$ & 99.95 & 0.180 & 0.0120 \\
\hline
\end{tabular}

\section{TABLE 6: RESULTS OF PRECISION STUDY}

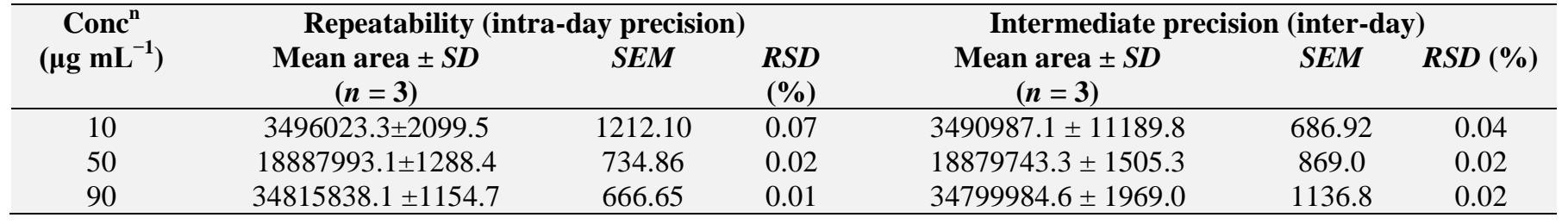




\section{Robustness and Ruggedness:}

Analytical methods need to be robust so that they can be used routinely without problems and can be easily transferred for use in another laboratory, if necessary. The intrinsic robustness of the HPLC method depends on a range of variables related to the method parameters, such as mobile phase composition (actual $\pm 10 \%)$, flow rate $(1.0 \pm$ $0.2 \mathrm{~mL})$, temperature $\left(25 \pm 2^{\circ} \mathrm{C}\right)$, wavelength $(211 \pm$ $1 \mathrm{~nm}$ ), and so forth. No significant effect was observed on system suitability parameters such as theoretical plates, tailing factor, capacity factor, and \% RSD of, when small but deliberate changes were made to chromatographic conditions. The RSD values ranged from 0.28 to $0.57 \%$ resume the robustness of the proposed method.

In method ruggedness, different columns (different lots with the same manufacturer), days, and analysts $(n=3)$ were performed. There results were summarized in Table 7.

TABLE 7: RESULTS OF METHOD ROBUSTNESS AND RUGGEDNESS STUDY.

\begin{tabular}{|c|c|c|c|c|c|c|}
\hline \multicolumn{3}{|c|}{$\begin{array}{l}\text { Mobile phase composition } \\
\text { (acetonitrile-water) }\end{array}$} & \multirow[t]{2}{*}{$\begin{array}{l}\text { Mean area } \pm \text { SD } \\
\quad(n=3)\end{array}$} & \multirow[t]{2}{*}{ SEM } & \multirow[t]{2}{*}{ Mean $t R \pm S D(\min )$} & \multirow[t]{2}{*}{ \%RSD } \\
\hline Original & Used & Level & & & & \\
\hline \multirow{3}{*}{$20: 80$} & $18: 82$ & -2 & $3495022.6 \pm 1165.5$ & 388.50 & $3.15 \pm 0.011$ & 0.34 \\
\hline & $20: 80$ & 0 & $3382742.6 \pm 1627.4$ & 542.46 & $3.18 \pm 0.017$ & 0.53 \\
\hline & $22: 78$ & +2 & $3456744.3 \pm 1907.1$ & 635.70 & $3.26 \pm 0.021$ & 0.64 \\
\hline \multicolumn{7}{|c|}{ Flow rate $(\mathrm{mL} \min -1)$} \\
\hline \multirow{3}{*}{1.0} & 0.8 & -2 & $3498833.3 \pm 1573.3$ & 524.43 & $3.17 \pm 0.012$ & 0.37 \\
\hline & 1.0 & 0 & $3394801.3 \pm 1151.9$ & 383.96 & $3.18 \pm 0.015$ & 0.47 \\
\hline & 1.2 & +2 & $\begin{array}{r}3554425.0 \pm 1847.4 \\
\text { Temperature }\end{array}$ & 615.80 & $3.21 \pm 0.010$ & 0.31 \\
\hline \multirow{3}{*}{25} & 23 & -2 & $3413937.5 \pm 1562.0$ & 1104.5 & $3.22 \pm 0.014$ & 0.43 \\
\hline & 25 & 0 & $3275772.5 \pm 1373.9$ & 971.50 & $3.18 \pm 0.009$ & 0.28 \\
\hline & 27 & +2 & $3452723.5 \pm 2406.3$ & 1701.5 & $3.25 \pm 0.011$ & 0.34 \\
\hline \multirow{4}{*}{211} & & & Wavelength(I & & & \\
\hline & 210 & -1 & $3509060.5 \pm 1299.0$ & 918.50 & $3.12 \pm 0.015$ & 0.48 \\
\hline & 211 & 0 & $3425812.5 \pm 1317.3$ & 931.50 & $3.18 \pm 0.012$ & 0.37 \\
\hline & 212 & +1 & $3482523.5 \pm 1977.8$ & 1398.5 & $3.32 \pm 0.019$ & 0.57 \\
\hline
\end{tabular}

\section{Selectivity:}

Selectivity of the method was evaluated by injecting the mobile phase, placebo blank, pure drug solution and tablet extract. No peaks were

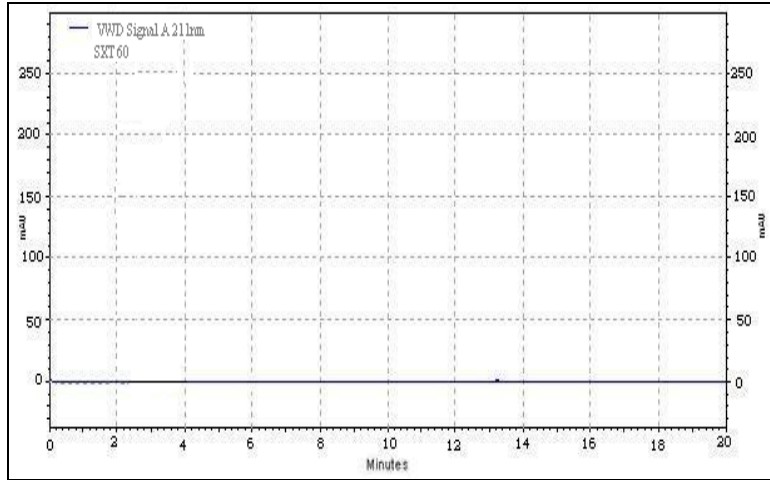

(a) Placebo blank observed for mobile phase and placebo blank and no extra peaks were observed for tablet extracts (Fig.3 (a) and 3 (b)).

FIG. 3: CHROMATOGRAMS OBTAINED FOR PLACEBO BLANK AND TABLET EXTRACT

\section{Stress Study:}

The degradation was performed as per the current practice of ICH guidelines ${ }^{33}$. Saxagliptin was found to be sensitive towards acid and alkali

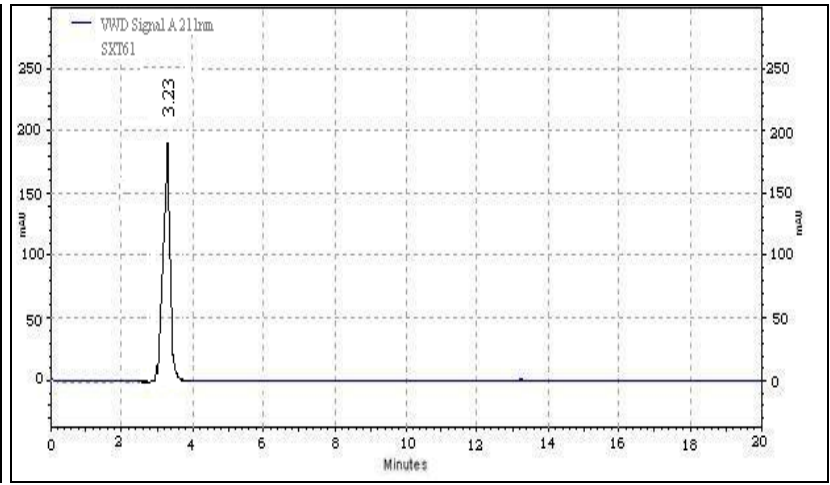

(b) Tablet extract 
degradation (water), and photolytic (1200K lux hours) conditions rather than under alkali stress conditions. No significant changes $(<1 \%)$ were observed for the chromatographic responses for the solutions analyzed with other stress conditions. Following are the \% degradation pattern of saxagliptin in oxidation, thermal, neutral, and photolytic conditions: $0.12,0.05,0.01$, and 0.32 . Fig.4 shows the degradation chromatograms of saxagliptin with the corresponding solvent as blank.

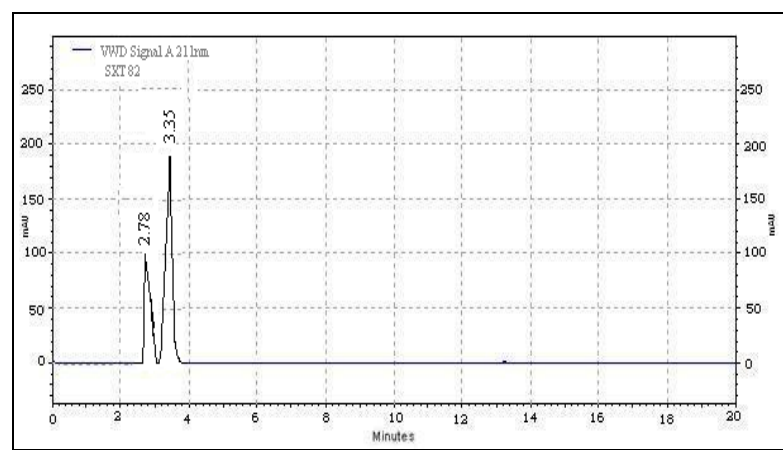

(a) $0.1 \mathrm{~N} H \mathrm{HCl}$ degradation

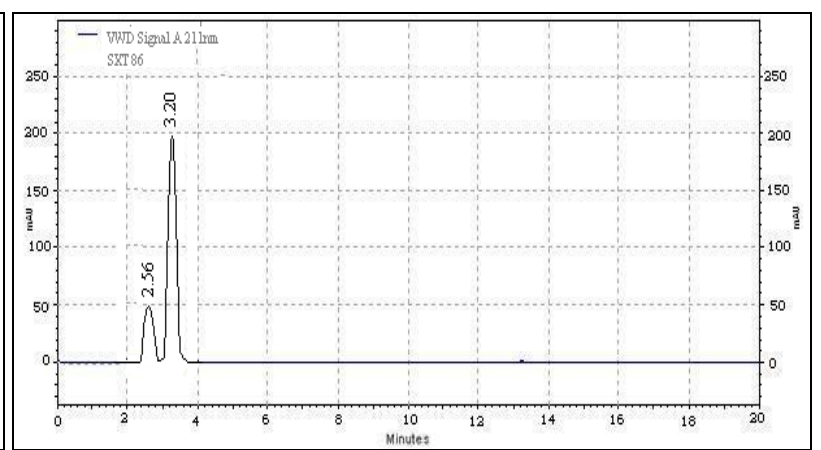

(b) $0.1 \mathrm{~N} \mathrm{NaOH}$ degradation

FIG. 4: CHROMATOGRAMS OBTAINED FOR FORCED DEGRADATION

CONCLUSION: A gradient RP-HPLC method was successfully developed for the estimation of saxagliptin in pharmaceutical dosage form. The QbD project aims to encourage debate about quality in the complete development of the drug in a systematic manner. From a solid-state point of view, QbD implementation involves the design of manufacturing processes based on a thorough scientific understanding of the properties and stability of the components of the drug at critical points throughout the development. The experimental design describes the scouting of the key HPLC method components including column, temperature, $\mathrm{pH}$, and mobile phase. The interrelationships are studied and the preliminary optimized conditions are obtained for each combination. Moreover, this approach ensures better design of products with fewer problems in development, reduces the number of trials required for post market changes, relies more on process and understanding and mitigation of risk, allows implementation of new technology to improve manufacturing without regulatory scrutiny, and enables possible reduction in overall costs of manufacturing resulting in less waste.

The validated method is specific, linear, precise, accurate, robust, rugged, and stable for 24 hours and can be applied for the determination in formulated form. The drug is stable in oxidative, thermal, photolytic and hydrolytic conditions and degrades in acidic, basic conditions. The potential of this QbD approach lies for the simultaneous determination of multiple forms of saxagliptin like pure drug, dosage forms and thus it should be implemented.

\section{REFERENCES:}

1. International conference on Harmonisation of technical requirements for registration of pharmaceuticals for human use; Step 4ICH Q8 (R) step-2, 2009.

2. International Conference on Harmonization of technical requirements for registration of pharmaceuticals for human use, ICH harmonized tripartite guideline, Pharmaceutical Development Q8 (R1), Draft Step 4, 2008.

3. Yu LX: Pharmaceutical quality by design: product and process development, understanding, and control. Pharmaceutical Research 2008; 25(4):781-791.

4. Vogt FG and Kord AS: Development of quality-by-design analytical methods. Journal of Pharmaceutical Sciences 2011; 100(3):797-812.

5. Li Y, Terfloth GJ and Kord AS: A systematic approach to RP-HPLC method development in a pharmaceutical QbD environment. American Pharmaceutical Review 2009; 12(4): 571-583.

6. Schweitzer M, Pohl M., Hanna-Brown M: Implications and opportunities of applying QbD principles to analytical measurements. Pharmaceutical Technology 2010; 34(2):52-59.

7. Krull I, Swartz M, Turpin J, Lukulay PH, and Verseput R: A quality-by-design methodology for rapid LC method development. Part I, LC-GC North America 2008; 26(12):1190-1197.

8. Krull I, Swartz M, Turpin J, Lukulay PH and Verseput R: A quality-by-design methodology for rapid LC method development. Part II, LC-GC North America 2009; 27(1): 48-61.

9. Kania DS, Gonzalvo JD, Weber ZA: Saxagliptin: a clinical review in the treatment of type 2 diabetes mellitus. Clin Ther 2011; 33:1005-1022. 
10. Kalaichelvi $\mathrm{R}$ and Jayachandran E: Validated Spectroscopic Method for estimation of Saxagliptin in Pure and from Tablet Formulation. International Journal of Pharmacy and Pharmaceutical Sciences2011; 3:179-180.

11. Ramalingam $\mathrm{K}$ and Jayachandran $\mathrm{E}$ : Extractive Spectrophotometric Estimation of Saxagliptin in Pure and in Pharmaceutical Dosage Form. American Journal of Pharma Tech Research 2012; 2:429-433.

12. Ramzia I. El-Bagary, Ehab F. Elkady and Bassam M. Ayoub: Spectrophotometric Methods Based on Charge Transfer Complexation Reactions for the Determination of Saxagliptin in Bulk and Pharmaceutical Preparation. International journal of Biomedical science 2012; 8(3):204-208.

13. Jeyabalan G and Nyola N: Analytical Method Development and Validation of Saxagliptine A Novel Dipeptidyl Peptidase Iv Inhibitors In Pure And Tablet Dosage Form by UV-Vis Spectroscopy. International Journal of Institutional Pharmacy and Life Sciences 2013; 3(5):152-158.

14. Vaishali V and Anand KD: Development and Validation of a Liquid Chromatographic Method for Estimation of Saxagliptin in Tablet Dosage Form. Asian Journal of Research in Chemistry 2013; 6:552-554.

15. Inturi S, Inturi $\mathrm{R}$ and Kumar IT: Validated novel LC determination of Saxagliptin in pure bulk and pharmaceutical dosage forms. International Journal of Pharmaceutical Research \& Development 2011; 3:845 52.

16. Chhabda PJ, Balaji M, Srinivasarao V, Ramakrishna K: Development and validation of simple stability indicating RP-HPLC method for analysis of saxagliptin and its forced degradation impurities in bulk drug and pharmaceutical dosage form. International Journal of Research and Development in Pharmacy and Life Sciences 2014; 3(3):993-1003.

17. Rao SP, Rama chandran D, Murali K and Srinivasu S: Stability indicating Isocratic Reverse phase HPLC Method with PDA detector for the Estimation of Saxagliptin in bulk drugs and in its Formulation. International Journal of Pharma Sciences2013; 3(5):333-342.

18. Dayyih WA, Tamimi L, Mallah E, Mansour K, Tawfiq A, Bustami M:Saxagliptin levels and its pharmacokinetic application in presence of sucralose in animals serum by HPLC method. International Journal of Pharmacy and Pharmaceutical Sciences 2015; 7(9):243-250.

19. Serife EKT, Mustafa VK and Demet D: An HPLC Method for the Determination of Saxagliptin in Human Plasma with Fluorescence Detection. Journal of Advances in Chemistry2013; 3:810-818.

20. Salvala S, Ettireddy S, Ciddi Veeresham: Development and Validation of a High Performance Thin Layer Chromatographic Method for Quantitative Analysis of Saxagliptin. American Journal of Analytical Chemistry 2015; 6:797-806.

21. Gao J, Yuan Y, Lu Y and Yao M: Development of A rapid UPLC-MS/MS Method for Quantification of Saxagliptin in Rat Plasma and Application to Pharmacokinetic Study. Biomed Chromatography2012; 26: 1482-1487.

22. Xiaohui X, Roger D, Huidong G, Lisa J, Christophera HS and Laura C: Liquid Chromatography and Tandem Mass Spectrometry Method for the Quantitative Determination of Saxagliptin and Its Major Pharmacologically Active 5Monohydroxy Metabolite in Human Plasma: Method Validation and Overcoming Specific and Non-Specific Binding at Low Concentrations. Journal of Chromatography B2012; 889-890:77-86.

23. Sridhar L, Goutami P, Vijay Darshan D, Ramakrishna K, Nageswara Raob Rand Prabhakar S: LC-ESI-MS/MS studies on saxagliptin and its forced degradation products. Anal. Methods2014; 6: 8212-8221.

24. International Conference on Harmonization Guideline on Validation of Analytical Procedures: Text and Methodology, Q2 (R1), 2005.

\section{How to cite this article:}

Daswadkar SC, Roy MA, Walode SG and Kumar CBM: Quality by Design Approach for the Development and Validation of Saxagliptin by RPHPLC with Application to Formulated Forms. Int J Pharm Sci Res 2016; 7(4): 1670-77.doi: 10.13040/IJPSR.0975-8232.7(4).1670-77.

All $\odot 2013$ are reserved by International Journal of Pharmaceutical Sciences and Research. This Journal licensed under a Creative Commons Attribution-NonCommercial-ShareAlike 3.0 Unported License.

This article can be downloaded to ANDROID OS based mobile. Scan QR Code using Code/Bar Scanner from your mobile. (Scanners are available on Google Playstore) 